\title{
Uma análise kantiana da dignidade humana: conjecturas reflexivas sobre as sentenças julgadas improcedentes em relação aos direitos fundamentais dos aprisionados
}

\author{
A Kantian analysis of human dignity: reflexive conjunctures about the \\ unfounded judge sentences in relation to the fundamental rights of the \\ imprisoned
}

\author{
ALESSANDRA AMADO ELIAS SONDA ${ }^{1}$ \\ KÁTIA SALOMÃO
}

\begin{abstract}
Resumo: O objetivo do presente trabalho é analisar, a partir da ótica Kantiana da dignidade humana, a possibilidade de realizar conjecturas reflexivas e críticas sobre as sentenças que foram julgadas improcedentes em relação aos direitos fundamentais dos aprisionados, ou seja, compreender teoricamente a jus filosofia de Kant tangível ao conceito de dignidade humana, na qual o mesmo passa a abordar uma ideia de um ser moral dentro de um sistema imperativo categórico, que é uma forma a priori, pura e independente do sujeito que tem autonomia e liberdade para agir e, no entanto, restrito de algumas ações que são consideradas ilícitas pelo Estado, que por sua vez irá punir o indivíduo que vier a praticar alguma conduta negativa. Todavia, esse motivo não dá ao Estado o direito de tirar do infrator direitos essenciais que estão previstos no artigo $5^{0}$ da Constituição Federal, destacando ainda as más condições que os aprisionados são colocados nas instituições carcerárias e o completo descaso dos entes do Poder Público em relação às observações sobre os direitos dos detentos inclusos na Lei de Execuções Penais.
\end{abstract}

Palavras-chave: Dignidade Humana. Autonomia. Condições carcerárias. Sentenças improcedentes.

\begin{abstract}
The objective of this study is to analyze from the perspective Kantiana human dignity, the possibility of reflective conjecture and criticism of the sentences that were dismissed in relation to the fundamental rights of the imprisoned, that is, theoretically understand the justice philosophy tangible Kant the concept of human dignity, where it begins to approach an idea of a moral being within a categorical imperative system, which is a form a priori, pure and independent of the subject who has autonomy and freedom to act and be, however, restricted to some actions that are accused as illegal by the state. The guy who comes to practice any immoral conduct, will have its right to denied freedom, however, that reason not of the state autonomy to exonerate the offender rights essences that are provided for in Article 5 of the Federal Constitution, highlighting also the bad conditions that trapped they are placed in custodial institutions, and the complete disregard of the entities of the Government in the observations on the rights of detainees included in the LEP.
\end{abstract}

Keyword: Human dignity. Autonomy. Prison conditions. Unfounded judge.

\section{Introdução}

A presente pesquisa cinge-se a analisar a não responsabilidade do Estado em

\footnotetext{
${ }^{1}$ Acadêmica do curso de Direito da UNIVEL - Faculdade de Ciências Sociais Aplicadas de Cascavel. Email: alesonda@hotmail.com

${ }^{2}$ Professora do curso de Direito da UNIVEL - Faculdade de Ciências Sociais Aplicadas de Cascavel. Email: salomao@univel.br
} 
virtude da não aplicação das leis aplicadas aos presos, colocando os mesmos em condições instáveis, o que, por sua vez, fere a dignidade da pessoa humana. Kant (2002), dentro da Teoria da Liberdade, acredita que o indivíduo tem autonomia e liberdade para agir e ser da forma que bem entender, porém ambas as ações são restringidas pelo Estado, evidenciando que mesmo após o indivíduo cometer uma infração, ou seja, algo de caráter negativo em relação às leis impostas, ele ainda continua tendo direitos que são inalienáveis e assegurados a sua pessoa e jamais deverão ser minimizados ou extintos.

Analisando os direitos fundamentais dos presos a partir da ótica Kantiana, percebe-se que eles não estão sendo tutelados como deveriam ser, vez que num Estado Democrático de Direito é dever do ente soberano harmonizar a liberdade dada ao indivíduo, banindo-o com arbitrariedades quando necessário, sem que seja deixada de lado sua dignidade (REALE, 2002).

As regras impostas à sociedade num todo implicam em direitos e deveres recíprocos entre o preso e o Estado, que só poderão ser limitadas em razões excepcionais expressamente previstas em lei. Segundo o Código Penal, ao preso é assegurado todos os direitos não afetados pela sentença penal condenatória e os direitos que devem ser limitados estão previstos em lei. Nesse sentido, Pereira (2013, p. 233) traz que "castigo penal apenas pode surgir da aplicação de um modelo que exclua o que é certo". Isto é, só existe a aplicação de uma norma penal quando o indivíduo age de forma contrária às leis, e apesar dessa conduta imoral existem direitos que continuam sendo inalienáveis aos aprisionados, como por exemplo o da dignidade humana, que incide no próprio direito à vida, o qual dá a qualquer pessoa, incluindo os aprisionados, direitos.

Embora existam inúmeros tratados internacionais que definem normas e orientações para uma melhor implementação das unidades penitenciárias de todo o mundo, observa-se que estas não estão sendo seguidas no Brasil. Ao não prestar a efetiva e gratuita assistência à saúde do preso, os Estados transgridem seus preceitos legais, constitucionais e internacionais, isto porque o artigo 196 da Constituição Federal preconiza: "a saúde é direito de todos e dever do Estado, garantido mediante políticas sociais e econômicas que visem à redução do risco de doença e de outros agravos e ao acesso universal igualitário as ações e serviços para sua promoção, proteção e recuperação".

Desta forma, Kant (2002), com enfoque principal nas más condições que os aprisionados se encontram em decorrência do completo descaso dos entes do Poder Público, comenta que surgem contradições que não podem ser omitidas, pois os aprisionados têm seus direitos tutelados pela Constituição Federal de 1988 no tocante ao respeito da sua dignidade humana, porém elas são asseguradas a partir do momento que o Estado nega ao aprisionado uma obrigação que ele deveria assumir. 


\section{Estado de Direito e Direitos Fundamentais}

A autonomia em Kant (1980) é uma ideia central da dignidade da pessoa humana, porém não se pode esquecer que a autonomia exerce-se em sociedade, por isso a necessidade de um fim conectado com as leis impostas, que remetem à ideia de que no final cada um não persegue apenas os seus fins, mas sim o de todos os outros, ou seja, a verdadeira autonomia é o respeito à dignidade humana de ação individual que leva em consideração todos os outros como fins em si mesmos. Sendo assim, o Estado foi originado com o objetivo de organizar melhor o homem em sociedade, garantindo o respeito da liberdade civil de qualquer um que faça parte desta coletividade, na forma que, mais uma vez, o Estado surge para respeitar e garantir os direitos humanos e fundamentais através do sistema jurídico.

Partindo da ideia acima suscitada, um Estado Democrático visa uma melhor organização social, capaz de proteger a coletividade e ao mesmo tempo as liberdades individuais, isto é, os direitos naturais do ser humano. Na concepção de Lima (2008), o Estado Democrático de Direito deve conceder aos cidadãos direitos com o fim de diminuir as desigualdades sociais existentes, almejando uma justiça social. Assim, será ofertado aos indivíduos direitos e deveres que, caso não cumpridos, deverão ser punidos, visando ressocializar para que o mesmo volte a conviver em sociedade de forma moral.

De acordo com Pereira (2013), a partir do momento em que o indivíduo realizar alguma conduta negativa, haverá o cumprimento de uma pena, que não pode implicar na perda ou minimização dos direitos fundamentais, já que são direitos de qualquer indivíduo, independentemente da situação em que se encontrar. Vale ressaltar que as regras impostas pelo Estado geram direitos e deveres recíprocos entre o preso e a Administração Pública, que não podem ser minorados ou abrandados em razão da situação jurídica do indivíduo. A administração penitenciária tem o dever de respeitar os direitos fundamentais dos reclusos, assegurando o exercício de todos os direitos que não foram atingidos pela sentença e a esse dever corresponde a obrigação do preso em respeitar as normas do regimento interno reguladas pelo estabelecimento.

Segundo a Constituição Federal de 1988 e a Lei de Execução Penal (LEP, nº 7.210, de 11 de julho de 1984), em seus artigos 12 e 14, o preso ou internado terá assistência material, em se tratando de higiene, instalações higiênicas e acesso ao atendimento médico, farmacêutico e odontológico. Todavia, a situação fática de muitos dos presos é de completa falta de higiene e inexistência de acompanhamento médico.

Muitos detentos se queixam de doenças gástricas, urológicas, dermatites, pneumonias e ulcerações, mas muitas vezes acabam não sendo atendidos adequadamente, afirmando que nem os remédios básicos estão à disposição para o 
devido tratamento. Conforme a Constituição Federal, usufruir da saúde é um dos direitos fundamentais de todo ser humano, sem nenhuma distinção. Caso seja verificado que a mesma está afetada, logicamente há uma distorção do direito à vida e à dignidade humana. Por isso, ao analisar a grave situação em que se encontram os aprisionados, expostos a uma precariedade de espaço físico e uma carência de atendimento à saúde, inexistência de higiene, entre outros, deparamo-nos com uma realidade invertida.

A dignidade, para Jacintho (2006), é irrenunciável e inalienável, constituindo elemento que qualifica o ser humano e como tal não pode ser destacada de tal modo que não se pode cogitar a possibilidade de determinado indivíduo perde-la. Portanto, como qualidade irrenunciável e integrante da própria condição humana, esta deve ser reconhecida, respeitada, promovida e protegida, não podendo ser retirada, já que existe em cada ser humano algo que lhe é inerente.

Baseado no acima exposto, torna-se visível que o Estado não vem cumprindo com sua obrigação em virtude da não aplicação das leis aplicadas aos presos, colocando-os em condições instáveis, que por sua vez ferem a dignidade da pessoa humana, que na ótica Kantiana, dentro de um sistema imperativo categórico, é inerente a qualquer indivíduo. Dessa forma, a partir do momento que ela é desconstituída, ingressa-se numa desorganização social que não deve ser propagada.

\section{Kant: desdobramentos sobre a Dignidade}

Com enfoque principal na tutela da dignidade humana, Jacintho (2006) afirma que esta é o ápice dentro do ordenamento jurídico, vez que é a base de todos os direitos constitucionais e ainda, um orientador estatal com o objetivo de acabar com as desigualdades que atentam dentro do meio social. O princípio da dignidade da pessoa humana nasce para proteger o ser humano, mantendo e garantindo o viver com dignidade e o respeito recíproco.

O homem busca a felicidade resultante de uma vida digna e geradora de condutas respeitosas e confiantes, no entanto, o indivíduo que não consegue alcançar a moral a partir de uma lei imposta, terá restrições de alguns dos seus direitos fundamentais. Para a reconstrução do interior do indivíduo que está aprisionado, o qual foi movido unicamente por uma razão de agir "errada", em conformidade com os ensinamentos Kantianos, deve-se internalizar que nem mesmo os aprisionados que irão ter alguns de seus direitos inerentes afastados podem ter sua dignidade ferida. Porém é nítido que em muitas situações tal premissa vem sendo rejeitada pelo Estado, que passa a corromper suas próprias leis, impedindo que o indivíduo aprisionado continue tendo seus valores tutelados sem qualquer autonomia.

Segundo Salomão e Svoliniski Júnior (2015), o homem sendo racional 
instrumentaliza sua razão, garantindo medidas que visam o bem individual e o da sociedade. A sociedade, por sua vez, é regida por normas realizadas anteriormente à ação do indivíduo, ou seja, antes de ocorrer uma ação que contrarie os costumes de determinada sociedade, o legislador pode tentar buscar uma forma de evitá-la, isto é, promulgar normas que sejam eficazes e que garantam, em contrapartida, o direito do indivíduo de se reconstruir moralmente e voltar à sociedade, de forma que consiga e queira agir de forma positiva. Em suma, o que ambos os autores expuseram é que, por mais que o indivíduo corrompa as leis que o Estado impõe, ele ainda continua tendo os direitos inerentes da sua pessoa assegurados, os quais devem ser preservados dentro de um sistema carcerário, que tem por única finalidade a regeneração do indivíduo para que esse se reinsira na sociedade com autonomia para agir e ser, porém dessa vez de forma que coadune com as leis.

De acordo com a tomada de direção de Kant (2002), na esfera dos direitos fundamentais pela vertente de conhecer o bem como a vontade de munir o sujeito pensante, o legislador, ao criar uma lei, deve sempre buscar a justiça como sendo uma garantia de direito. A Constituição Federal do Brasil de 1988, artigo 1ํㅡ, inciso III, fala sobre a questão da dignidade, a qual é caracterizada por fazer parte do sujeito no plano do Estado Democrático de Direito. Tal inciso da Constituição Federal nos traz um valor incondicional e incomparável, não tendo como valorar a dignidade, pois já é do ser humano.

Aranha (2005) considera a incompletude humana, a ambiguidade dos desejos e a possibilidade aberta de uma construção de liberdade como previsíveis, ou seja, a passa uma ideia de que a qualquer momento pode-se acertar como também errar. Dessa forma, propõe-se a construir um mundo melhor, no entanto todos os indivíduos estão igualmente dispostos a persistir nas ações movidas pelo egoísmo, inveja e cupidez, a qual dá ao Estado o direito de frear os erros e corrigi-los para que a sociedade caminhe junta, com um único fim, que é o bem comum. Sarlet enfatiza:

Não restam dúvidas de que a dignidade é algo real, já que não se verifica maior dificuldade em identificar claramente muitas das situações em que é espezinhada e agredida, ainda que não seja possível estabelecer uma pauta exaustiva de sua violação. (SARLET, 2009, p.97)

Ao partir da ideia de que cada pessoa é única e insubstituível, nota-se que o resultado é que todos somos iguais e dignos de respeito, como Kant (2002) defende: a dignidade humana considera que cada ser humano é um fim em si mesmo e ninguém pode ser meio para o que quer que seja.

O autor traz ainda que a humanidade se constrói pela conduta e se transforma num processo contínuo. Assim, o aprisionado, ao ser colocado num meio propício para uma regeneração moral, pode voltar à sociedade de forma que possa contribuir socialmente com as normas impostas, porém presume-se que se o aprisionado for 
colocado em um meio impróprio de regeneração as chances de ele voltar à sociedade de forma digna para agir e ser passa a ser pequena, quase improvável, já que sua dignidade foi violada.

Sarlet (2009), em relação à ótica Kantiana, considera que a dignidade é algo real, vivenciado de forma concreta por cada ser humano, independentemente da forma que o Estado a coloca. Porém, verifica-se, sem muita dificuldade, situações em que a mesma passa a ser agredida, sendo possível estabelecer uma pauta exaustiva de violação do principal direito inerente a toda pessoa humana, dando enfoque neste trabalho aos direitos dos aprisionados, que por sua vez estão sendo submetidos às péssimas condições que o próprio Estado os coloca, causando-lhes danos, os quais distorcem as conjecturas expostas pela Constituição Federal, pela LEP e pelos tratados internacionais criados para implementar nas penitenciárias uma maior assistência ao detento, visando jamais minimizar, muito menos ferir, a dignidade humana.

Para Sandel (2012), na sua obra "Justiça - O que é fazer a coisa certa", agir com liberdade seria o sujeito aceitar as normas impostas pelo Estado e internalizar que o agir moral está ligado a essas normas. Nessa obra, Sandel relata que Kant apresenta uma proposta alternativa para a questão dos direitos e deveres, isto é, ele não se fundamenta na ideia de que cada indivíduo é dono de si próprio, ou na afirmação de que a vida e a liberdade de cada ser sejam um presente de Deus, pelo contrário, a ideia dele é que cada cidadão é um ser racional, merecedor de respeito e dignidade. Seu conceito de liberdade não é agir livremente para alcançar um determinado fim, e sim escolher o fim em si mesmo de forma moral ao que é lhe imposto.

Portanto, o Estado, como ente soberano, deve atender todas as necessidades do indivíduo e, no caso dos aprisionados, colocá-los em situações que lhes permitam voltar para o meio social com autonomia e vontade de agir e ser moralmente. Dentro da concepção Kantiana, entender o que é agir com autonomia é comparar tal qual com seu oposto, heteronímia. Quando o indivíduo age de forma heterônoma, age de acordo com determinações divergentes a lei. Mas, de acordo com Kant (2002), o valor moral de uma ação não consiste em suas consequências, mas na intenção como a qual é realizada, ou seja, o que importa é fazer a coisa certa e não fazer a coisa certa por algum motivo exterior a ela, que no caso concreto passa a ser a lei.

\subsection{Autonomia Versus Heteronomia: Caminhos Para A Dignidade}

A autonomia Kantiana propõe que o sujeito dê a si mesmo uma lei que deverá obrigatoriamente obedecer. A origem da palavra autonomia é esclarecedora, "auto" corresponde a si mesmo e "nomos" é lei, ou seja, "dar a lei a si mesmo", nada mais é do que a capacidade de agir e ser, como aponta Kant (2002), sem que o digam como pensar, agir ou até como tomar alguma decisão. Dessa forma, a autonomia 
demonstra que o homem tem a capacidade de ser dono de si e livre de toda dependência.

O valor moral Kantiano está no modo como a máxima do agir foi determinada: se a mesma foi influenciada por sentimentos, paixões ou pensamentos de outros não será uma ação moral; por outro lado, se na razão for verificada a intenção de agir, reveste-se de caráter moral e será endossada igualmente por qualquer ser racional. Nessa busca, Kant (2002) procura fundamentar uma metafísica dos costumes e posteriormente faz uma crítica da razão prática que, segundo ele, é responsável pela ação humana. Dessa forma, a razão é direcionada ao conhecimento, isto é, determina seu objeto através de uma ação, ou seja, a metafísica só poderá ser encontrada na fundamentação do domínio do mundo moral. Para o filósofo, a razão é sempre universal, seja ela pura ou prática, podendo variar seus conteúdos no espaço e no tempo, mas não sua forma enquanto atividade racional, sendo todo e qualquer indivíduo movido pela sua própria razão e limitado pelo Estado.

Entende-se, portanto, que a autonomia da vontade é aquela que é para si mesmo a sua lei, independentemente da natureza dos objetos do querer. Para ser um indivíduo moral é preciso ser livre. Desse modo, aquela independência e liberdade em sentido negativo não deve ser minimizada, e sim valorada, para que o aprisionado reconstitua a vontade de dar a si novas leis, desta vez em consonância ao bem da sociedade.

Logo, pode-se dizer, junto com os ensinamentos trazidos por Kant (2002), que a vontade livre e a vontade submetida às leis morais são as mesmas coisas, vez que a lei é dada pela própria razão, resgatando uma auto coação, um autodidatismo, no qual ninguém, nem mesmo algo de caráter exterior, pode dizer como deve-se agir. Portanto, a lei moral, "pura forma legislativa" da qual todo indivíduo se torna imediatamente consciente, age de duas formas ao determinar a vontade: ela nega toda a propensão de uma inclinação ao tornar-se lei ou gera um sentimento de dor pelo fato de causar dano a todas as inclinações.

Por fim, frisa-se que a heteronímia, que significa nada mais que dependência, submissão, obediência, formada do radical grego "hetero", que significa "diferente", e “momos", que significa "lei", portanto, é a aceitação de normas legalmente reconhecidas como válidas, com o objetivo de orientar a consciência do indivíduo que vai discernir o valor moral de seus atos. Passa-se então a ter um embate, já que a autonomia não os coloca num estado de reflexão sobre as limitações que lhe são impostas a partir da heteronímia trazida, e a própria consciência de cada sujeito. Essa máxima é o princípio prático de que, segundo Kant (2002), fazer certo tipo de coisa em determinada situação por algum motivo ou alguma razão é a versão generalizada da intenção consciente da pessoa em praticar a ação. 


\section{A LEP e as condições carcerárias: problemática à Dignidade Humana}

A Declaração Universal de Direitos Humanos (DUDH) é um documento com marco na história dos direitos humanos a partir de 1948, sendo direcionada a todo e qualquer ser humano. Ocorre, porém, que especificamente em relação aos aprisionados, não raras vezes os mesmos têm seus direitos atentados pelo próprio Estado, seja pela discriminação ou pela precariedade das condições que este fornece aos condenados que cumprem pena em entidades carcerárias.

Segundo dispõe os princípios fundamentais que constituem a República Federativa do Brasil, encontra-se a dignidade da pessoa humana, elencada no artigo $I^{\circ}$, III, da Carta, onde o respeito, a proteção e uma existência digna são considerados mínimos direitos que deveriam ser assegurados de forma plena a todos os cidadãos brasileiros sem qualquer distinção.

Segundo Sarlet, no que diz a respeito ao princípio constitucional referido:

O princípio constitucional visa a garantir o respeito e a proteção da dignidade humana não apenas no sentido de assegurar um tratamento humano e não degradante, e tampouco conduz ao mero oferecimento de garantias à integridade física do ser humano. Dado o caráter normativo dos princípios constitucionais, princípios que contêm os valores ético-jurídicos fornecidos pela democracia, isto vem a significar a completa transformação do direito civil, de um direito que não mais encontra nos valores individualistas de outrora o seu fundamento axiológico. (SARLET, 2006, p. 131)

A Lei de Execução Penal traz uma série de obrigações do Estado, bem como assistência, respeito, trabalho, avaliação, entre outras, em relação ao presidiário. De acordo com a LEP, constituem direitos do preso: alimentação suficiente e vestuário; atribuição de trabalho e sua remuneração; Previdência Social; constituição de pecúlio; proporcionalidade na distribuição do tempo para o trabalho, o descanso e a recreação; exercício das atividades profissionais, intelectuais, artísticas e desportivas anteriores, desde que compatíveis com a execução da pena; assistência material, à saúde, jurídica, educacional, social e religiosa; proteção contra qualquer forma de sensacionalismo; entrevista pessoal e reservada com o advogado; visita do cônjuge, da companheira, de parentes e amigos em dias determinados; chamamento nominal; igualdade de tratamento, salvo quanto às exigências da individualização da pena; audiência especial com o diretor do estabelecimento; representação e petição a qualquer autoridade, em defesa de direito; contato com o mundo exterior por meio de correspondência escrita, da leitura e de outros meios de informação que não comprometam a moral e os bons costumes; atestado de pena a cumprir, emitido anualmente, sob pena da responsabilidade da autoridade judiciária competente; é garantida a liberdade de contratar médico de confiança pessoal do internado ou do submetido a tratamento ambulatorial, por seus familiares ou dependentes, a fim de orientar e acompanhar o tratamento. 
Em seu artigo $1^{\circ}$ define a natureza da execução penal, referindo que "a execução penal tem por objetivo efetivar as disposições de sentença ou decisão criminal e proporcionar condições para a harmônica integração social do condenado e do internado". No entendimento abrangente de Mirabete:

A função da execução penal deita raízes entre três setores distintos: no que respeita à vinculação da sanção e do direito subjetivo estatal de castigar, a execução entra no direito penal substancial; no que respeita à vinculação como título executivo, entra no direito processual penal; no que toca à atividade executiva verdadeira e própria, entra no direito administrativo. [...] Ela é uma atividade complexa. (MIRABETE, 2000, p. 86)

Segundo Mirabete (2000), as penas privativas de liberdade têm a finalidade de ressocilializar, recuperar, reeducar ou educar o condenado, tendo uma função educativa que é de natureza jurídica. Aplica-se a exceção quando esses "direitos" não são devidamente respeitados, porém não é o que se evidencia atualmente, tendo em vista que efetivamente não há oferecimento de condições dignas aos direitos humanos dentro dos presídios, sendo o Estado omisso no que concerne a aplicação das suas leis.

A LEP, em seu conteúdo traz uma série de garantias, direitos e deveres dos presos. Possui, em seu fundamento constitucional, no que concerne a aplicação dos direitos fundamentais para aqueles que infringem a lei penal, que devem sim cumprir com a pena estabelecida. É importante destacar que não se tem pretensão alguma de manifestar defesa quanto ao cumprimento da pena imposta ao condenado, pelo contrário, se a Constituição Federal concedeu ao Poder Judiciário, como instrumento de atuação do Estado, o poder de velar pela reprimenda da criminalidade com todo o aparato que lhe é peculiar, confirma-se que isso seja necessário à sociedade, embora possa ser remodelado em alguns aspectos. Entretanto, na linha de igualdade, o condenado também tem direito às condições dignas e humanas para pagar pelo seu erro, conforme lhe garante a própria Constituição.

O desrespeito aos direitos humanos é tão grave que por vezes a situação dos presídios é mais penosa do que das favelas e comunidades das quais os presos provêm. Essa negligência do Estado deve ser visualizada e modificada, pois não se trata da falta de condição financeira do Estado, e sim da prioridade que o Estado dá a determinadas áreas.

Nesse contexto, entende-se o acórdão a seguir como um desabafo dos juízes, na tentativa de cumprirem com o estabelecido na própria legislação, sem ir contra os direitos humanos: 
INDEFERIU LIMINARMENTE O WRIT - ADMISSIBILIDADE DA VIA ELEITA - DIREITO LÍQUIDO E CERTO DEMONSTRADO. SUPERLOTAÇÃO DE PRESÍDIO - SEGREGADOS MANTIDOS ACORRENTADOS EM PILARES - VIOLAÇÃO AO PRINCÍPIO DA DIGNIDADE DA PESSOA HUMANA - SISTEMA JURÍDICOPOLÍTICO DE FREIOS E CONTRAPESOS (CHECKS AND BALANCES) - DEVER DO PODER JUDICIÁRIO DE CORRIGIR FALTAS E OMISSÕES DOS DEMAIS PODERES QUE VIOLAM DIREITOS FUNDAMENTAIS - DECISÃO MANTIDA, NO PONTO.

Diante da inobservância, pelo Executivo, de direitos fundamentais dos segregados que estão aos seus cuidados - sobretudo a dignidade da pessoa humana -, deve o Poder Judiciário forte no sistema de freios e contrapesos - que a Constituição adota, porque democrático e de direito o Estado - atuar de modo a corrigir-lhes as faltas, com vistas ao equilíbrio e ao alcance dos fins sociais a que referido sistema almeja, adotando as medidas necessárias à restauração dos direitos violados. DECISÃO JUDICIAL QUE LIMITA O NÚMERO DE PRESOS POR CELA, COM FUNDAMENTO NA LEI DE EXECUÇÃO PENAL E NOS DIREITOS INDIVIDUAIS DO SEGREGADO, E FIXA MULTA AO ESTADO EM CASO DE DESCUMPRIMENTO - REALIDADE CARCERÁRIA QUE IMPEDE O CUMPRIMENTO DA DETERMINAÇÃO - IMPOSIÇÃO QUE SÓ PODE SER LEVADA A EFEITO A LONGO PRAZO PONDERAÇÃO DE INTERESSES - DIREITOS INDIVIDUAIS DO PRESO APLICADOS EM MENOR GRADUAÇÃO QUANDO CONFLITADOS COM OS DIREITOS DO CORPO SOCIAL, CONSUBSTANCIADOS NO DIREITO À VIDA, À INTEGRIDADE FÍSICA E À SEGURANÇA - EXCLUSÃO DA MULTA PROCEDÊNCIA PARCIAL. (BOSCHETTI; LOPES)

Em observância à jurisprudência trazida acima, as condições desumanas dos presídios são de fato um problema nacional. O caso citado diz respeito ao agravo regimental em mandado de segurança interposto pelo Estado de Santa Catarina após ter sido condenado em sentença de $1^{\underline{0}}$ grau ao pagamento de multa diária quando da não observância das condições dos presos, bem como de ter ferido a dignidade da pessoa humana dos encarcerados, pois os mesmos estavam presos por algemas em móveis e grades devido às superlotações das celas.

As condições das penitenciárias são degradantes e, de acordo com o acórdão da jurisprudência e com Motta (2013), as doenças são terríveis e tem se alastrando de forma imensurável, estando os presos submetidos a risco de vida ante tanta precariedade. O pior de tudo é que o Estado passa a ignorar tal situação, dando por culpados os índices de criminalidade.

Para Junqueira (2005), o dever da prevenção, do oferecimento de condições, consciência e mudanças é dever do próprio Estado, não devendo os encarcerados serem submetidos a condições degradantes devido à falha do próprio garantidor dos seus direitos, dando início a uma luta pelos direitos humanos dos encarcerados, 
sendo o Estado o único fornecedor das condições, como educação e medidas profiláticas, evitando que a criminalidade aumente.

Tendo em vista os aspectos considerados acima, percebe-se a disparidade existente entre a lei formal e a prática, o que acaba gerando enormes distorções no plano fático.

O sistema normativo do Estado, especificamente através da LEP, prevê uma série de direitos e garantias do apenado, conforme previamente mencionado, que estão sendo desrespeitadas pelo próprio Estado. Ao violar tais direitos, que são garantias mínimas para o cumprimento da pena e integridade do preso, como, por exemplo, a individualização da pena e a classificação dos condenados, o Estado fere a dignidade do preso, que, segundo Kant (2002), jamais pode ser minimizada ou extinta. Operadores do direito reconhecem que devido às condições degradantes existentes para o cumprimento da pena, torna-se impossível que esta realize seu escopo primordial, que é a ressocialização do indivíduo. Percebe-se assim a utopia que a ressocialização representa para o sistema penitenciário brasileiro. Vislumbram-se algumas possíveis soluções: a educação na sua forma preventiva, encarada como solução a longo prazo; a atenção estatal ao problema, garantindo as previsões legais para a execução da pena; e/ou a criação de um sistema que vise diferentes formas e locais para o cumprimento de penas, conforme a gravidade do delito (semelhante à individualização da pena proposta pela LEP).

\section{Improcedências sentenciais: implicações sobre a Dignidade Humana}

Inúmeras foram as sentenças julgadas improcedentes ${ }^{3}$, porém uma está exposta neste trabalho com o fim de expor de forma pacificada a afronta a dignidade humana dos aprisionados, vez que trata de indenização por danos morais, materiais, entre outros, garantias que jamais deveriam ser negadas a qualquer preso, dando enfoque que o mesmo tem seus direitos tutelados. Porém, na prática sua dignidade é ferida a partir do momento que ele passa a não ter acesso às condições básicas, ressaltando a incompatibilidade da lei com o agir imoral do Estado, que julga improcedentes os pedidos feitos, sendo uma afronta, partindo da ideia de que a

\footnotetext{
${ }^{3}$ Inúmeros são os exemplos de sentenças julgadas improcedente em relação a dignidade do aprisionado, aqui cita-se: Apelação Civil. Responsabilidade Civil. Ação de por Danos Indenização Morais. Réu do Estado de Santa Catarina. Morte de Detento. Demanda Ajuizada pelo Filho do Falecido. Dano Moral Reflexo ou em Ricohete. Destituição do Poder Familiar. Irrelevância no caso concreto. Legitimidade ativa constatada. Preliminar Repelida. Certidão de Óbito Atestando "Insuficiência Respiratória Aguda". Caquexia. Doença pelo HIV Resultando em Doença Infecciosa. Insuficiência Respiratória e Desnutrição Profunda Resultantes do Vírus da Imunodeficiência Adquirida - HIV. Apenado, ademais, Acometido de Tuberculose. Demonstração de que o Vírus foi adquirido após o Ingresso no Sistema Carcerário. Irrelevância. Ônus Probatório Inverso. Dever do Estado de Realizar Exames Médicos nos Presos Ingressos, Constando Preexistente Moléstia. Inocorrência na espécie. Omissão Específica. A Responsabilidade Civil Objetiva. Artigo37, § 6o, da Constituição Federal. Indenização pelo Dano moral Devido. Pensionamento alimentar igualmente procedente. Sentença de Improcedência do Pedido. Recurso Negado.
} 
dignidade deve ser sempre preservada e permanecer inalterada em qualquer situação em que a pessoa se encontre, até mesmo aprisionada, pois o indivíduo deve permanecer em condições que seus direitos sejam assegurados, mantendo os direitos que não foram atingidos pela sentença penal. Assim, o objetivo não é livrar o infrator da pena, e sim colocar o mesmo em condições dignas, que a própria Constituição Federal dispõe, a fim de que ele tenha uma reinserção no meio social de forma digna e justa.

Vale ressaltar que a não responsabilidade do Estado em virtude da não aplicação das leis submetidas aos presos coloca-os em condições instáveis, que ferem a dignidade da pessoa humana, a qual Kant (2002), dentro de um sistema imperativo categórico, acredita que seja inerente ao indivíduo a autonomia e a liberdade para agir e ser. Porém, ambas restringidas pelo Estado, acusam como ilícito o agir imoral de tal, evidenciando que, mesmo após o indivíduo cometer uma infração, ele ainda deve ter seus direitos inalienáveis assegurados.

Neste enfoque, depara-se com um sério problema que se insere no âmbito do Direito Constitucional, com influência no Direito penal, a ser elucidado por esta pesquisa, que defende a ideia de que da mesma forma que os presos devem respeitar as regras e as normas do presídio, a instituição carcerária tem o dever de garantir ao aprisionado todos os direitos fundamentais da dignidade da pessoa humana. Este é um princípio norteador, o qual o Poder Público deve respeitar, independentemente de merecimento pessoal ou social, vez que, segundo Kant (2002), todo ser humano é um fim em si mesmo, sendo a dignidade inerente da pessoa. Mas a questão torna-se aprofundada na medida em que os detentos além de não terem acesso às condições básicas que resultem no respeito a sua dignidade, ainda tem o seu direito negado de exigir do Estado a tutela de seus direitos. É sabido que em casos de pedidos de reparação de danos físicos, morais, ou de quaisquer espécies, os tribunais sempre julgam como improcedentes tais sentenças. Logo, os detentos estão submetidos a condições que colocam sua vida em risco e em contrapartida o Estado nega-lhes o direito de clamar por dignidade.

Os direitos fundamentais dos presos, portanto, não vêm sendo tutelados como deveriam ser, vez que, segundo Miguel (2003), o Estado Democrático de Direito é o ente soberano e tem por objetivo harmonizar a liberdade dada ao indivíduo e o poder estatal, banindo-o com as arbitrariedades, cujo cumprimento da pena não pode implicar jamais na perda ou minimização dos direitos fundamentais.

Essas regras especiais implicam em direitos e deveres recíprocos entre o preso e a administração, sem que sejam deixados de lado os direitos fundamentais, como direitos inerentes a todos os cidadãos, que só podem ser limitados em razão excepcional dos casos expressamente previstos em lei.

Segundo o Código Penal, ao preso é assegurado todos os direitos não afetados 
pela sentença penal condenatória, sendo que seus direitos limitados estão previstos em lei. A lei de execução penal (LEP), em seu artigo 158 , parágrafo $\mathbf{1}^{\mathbf{0}}$ prevê expressamente as ocasiões em que os direitos podem sofrer limitação dentro do presídio. Sendo assim, os presos têm assegurado, tanto pela Constituição Federal quanto pela Lei de Execução Penal, seu direito à vida, à dignidade, à liberdade, à privacidade, etc. O princípio da dignidade da pessoa humana assegura e determina os contornos de todos os demais direitos fundamentais, o que implica que a dignidade deve ser preservada e permanecer inalterada em qualquer situação em que a pessoa se encontre. A prisão deve se dar em condições que assegurem o respeito à dignidade e os condenados devem manter os direitos não atingidos pela sentença penal condenatória, como já suscitado.

A humanidade da pena determina que o homem não pode ser tratado como meio, mas como fim, como pessoa, o que impõe limitação à quantidade e à qualidade da pena e, consequentemente, o respeito à vida e a proibição de penas cruéis ou degradantes, incluindo o rigor desnecessário e as privações indevidas impostas aos condenados.

A sentença exposta a seguir foi julgada improcedente em primeira instância. Ocorre que o aprisionado contraiu doença infecciosa pelas más condições da instituição carcerária que estava inserido e a nítida precariedade de higiene que a mesma oferecia. Ao não receber assistência à saúde, um direito fundamental de qualquer indivíduo, a família do detendo que veio a falecer recorre ao Poder Público pedindo indenizações por danos morais e materiais e tem seu direito negado em primeira instância pelo Estado, que dá como justificativa culpa exclusiva do indivíduo que estava naquela situação porque veio a violar um direito imposto. Em um segundo momento, após a sentença proferida, a decisão do juízo aquo foi alterada, reafirmando que a dignidade do mesmo havia sido gravemente ferida. $\mathrm{O}$ estado transgride em todos seus preceitos legais, sendo impossível uma reinserção com os meios putrefatos que o Estado coloca os detentos, uma realidade que não deve ser ignorada e sim alterada.

\section{Conclusão}

Aos condenados à pena privativa de liberdade deverão ser propiciadas as condições para uma existência digna, velando-se por sua vida, saúde e integridade física e moral. A humanidade da pena assegura ainda o direito de cumpri-la perto dos familiares, com direito à intimidade, privacidade, liberdade de expressão e ao sigilo da correspondência.

Kant (2002) estabelece que o sujeito seja o fim em si mesmo, e descarta a possibilidade deste ser usado para quaisquer outros fins, e que se torna imoral quando contraria a uma lei suprema. Porém, tais direitos, mesmo minimizados, continuam sendo inalienáveis por se tratar de uma condição efetiva e equitativa da 
dignidade da pessoa humana, vez que não pode ser destrata pelo Estado como vem sendo em muitos casos.

O relator Stanley da Silva Braga (2014, n.2014.069494-1) apresentou um caso de um aprisionado que faleceu após ter contraído, dentro do sistema carcerário, tuberculose - doença que vem a ser infecciosa, podendo causar insuficiência respiratória, desnutrição profunda, entre outros sintomas - que veio a se instalar no corpo do detento, pelo fato de se encontrar instalado em más condições dentro do sistema carcerário. Neste caso, a sentença foi julgada improcedente, negando a indenização por danos morais aos familiares do falecido. Tal improcedência fere os direitos fundamentais e humanos da dignidade da pessoa humana.

No caso citado, o detendo, além de não ter acesso às condições básicas que deveriam ser conferidas a ele, tem sua dignidade deixada de lado pela condição que se encontra, ou seja, tem seu direito negado pelo próprio Estado, que o abstém de uma obrigação que deveria assumir e cumprir, pois neste caso era de direito dos familiares que fosse assegurada a indenização por danos morais, já que o Estado feriu um direito, agindo de forma imoral.

Segundo Kant, uma ação como meio tem o objetivo único de alcançar determinado fim, e o imperativo categórico indica que a ação é necessária e boa em si, independentemente dos fins que se possa alcançar com ela. Portanto, o Estado, ao negar indenização ao cidadão, ora aprisionado, sendo que deveria assegurar tal direito por ser inerente à dignidade de sua pessoa humana, desrespeita as condições dignas que a Constituição Federal dispõe.

Assim, conclui-se que o objetivo não é livrar o infrator da pena, e sim colocar o mesmo em condições dignas que a própria Constituição Federal dispõe, a fim de que ele tenha uma reinserção no meio social de forma digna e justa.

\section{Referências}

ARANHA, Maria L. de A.; MARTINS, Marta. H. P. Temas de Filosofia. São Paulo: Moderna, 2001.

BONJOUR, Laurence; Baker ANN. Filosofia - Textos Fundamentais Comentados. Porto Alegre: Artmed, 2010.

BOSCHETTI, Mauro Luis; LOPES, Mônica Tais Medeiros. Dignidade do Presidiário, Direitos Humanos e o Sistema Prisional. Disponível em:

$<$ http://www.viajus.com.br/viajus.php?pagina=artigos\&id=2830\&idAreaSel=16\&seeArt=yes $>$. Acesso em: o9 out. 2016.

BRAGA, Stanley da Silva. TJ-SC - Apelação Cível: AC 20140694941 SC 2014.069494-1 (Acórdão). Disponível em:

$<$ http://www.jusbrasil.com.br/jurisprudencia/busca?q=NECESSIDADE+DE+CONTINUIDA

$\left.\mathrm{DE}+\mathrm{DO}+\mathrm{TRATAMENTO}+\mathrm{M} \% \mathrm{C}_{3} \% 89 \mathrm{DICO}+\mathrm{DOMICILIAR+(HOME}+\mathrm{CARE}\right)>$

GIL, Carlos. Métodos e Técnicas de Pesquisa Social. São Paulo: Atlas Editora, 2010. 
JACINTHO, Jussara Maria Moreno. Dignidade humana - Princípios Constitucionais. Curitiba: Juruá. 2006.

JUNQUEIRA, Ivan de Carvalho. Dos direitos humanos do preso. São Paulo: Lemos e Cruz, 2005 .

KANT, Immanuel. Fundamentação da metafísica dos costumes. Lisboa: Edições 70, 2002.

KANT, Immanuel. Crítica da razão pura. São Paulo: M. Fontes, 2002.

KANT, Immanuel. Fundamentação da Metafísica dos Costumes e Outros Escritos. Trad. Paulo Quintela. Lisboa - Portugal: Edições 70, 2005.

KANT, Immanuel. Doutrina do Direito. Trad. Edson Bini. São Paulo: Ícone, 1993. O Fondazione de/ia Metafísica dei Costumi. Trad. Pietro Chiodi. Roma: Laterza, 1980.

LAKATOS, Eva. Fundamentos da Metodologia Científica. São Paulo: Atlas, 2010.

LIMA, Francisco Arnaldo Rodrigues de. O princípio da dignidade da pessoa humana nas constituições do Brasil. In: Âmbito Jurídico. Rio Grande, XV, n.97, fev. 2012. Disponível em: $<$ http://www.ambito-

juridico.com.br/site/index.php?n_link=revista_artigos_leitura\&artigo_id=11138>. Acesso em:

MIRABETE, Julio Fabbrini. Execução penal: comentários à Lei nº 7.210, de 11-7-84. 9. São Paulo: Atlas, 2000.

MOTTA, Artur Francisco Mori Rodrigues. A dignidade da pessoa humana e sua definição, Rio Grande, XVI, n. 119, dez. 2013. Disponível em: <http://www.ambitojuridico.com.br/site/?n_link=revista_artigos_leitura\&artigo_id=14054>. Acesso em:

PEREIRA, Ângela Miranda. Os direitos do preso à luz do princípio da dignidade da pessoa humana. In: Âmbito Jurídico. Rio Grande, XVI, n. 116, set. 2013. Disponível em:

$<$ http://www.ambito-

juridico.com.br/site/?n_link=revista_artigos_leitura\&artigo_id=13682>. Acesso em:

PIMENTEL, Ademir Paulo. TJ-RJ - AGRAVO DE INSTRUMENTO : AI oo3609804200881900oo RIO DE JANEIRO CAPITAL. Disponível em: <http://tj-

rj.jusbrasil.com.br/jurisprudencia/395812583/agravo-de-instrumento-ai3609804200881900oo-rio-de-janeiro-capital-45-vara-civel/inteiro-teor-395812591>. Acesso em:

REALE, Miguel. Filosofia do Direito. 19 ed. São Paulo: Saraiva. 2002.

REALE, Miguel. Lições preliminares do direito. 24. Ed. São Paulo: Saraiva, 1988.

SANDEL, Michael. Justiça: o que é fazer a coisa certa. Trad. Heloisa Matias e Maria Alice Máximo. 6 ed. Rio de Janeiro: Civilizações Brasileiras, 2012.

SARLET, Ingo Wolfgang. Dimensões da Dignidade. Porto Alegre: Livraria do Advogado. 2009.

SARLET, Ingo Wolfgang. A eficácia dos Direitos Fundamentais - Uma teoria geral dos Direitos Fundamentas na perspectiva Constitucional. Porto Alegre: Livraria do Advogado. 2009.

SARLET, Ingo Wolfgang. Org. Constituição, Direitos Fundamentais e Direito Privado. Porto Alegre: Livraria do Advogado. 2006.

Submissão: 15.10.2018 / Aceite: 10.12.2019

Diaphonía, e-ISSN 2446-7413, v. 6, n. 1, 2020 